\title{
As demandas de pesquisas sobre proteção social no Mercosul: exigências para 0 Serviço Social
}

\section{The demands of research into social protection in Mercosur: requirements for Social Work}

\section{esumo}

Este artigo aponta elementos sobre o debate a respeito das propostas relativas à proteção social que vêm sendo delineadas no contexto dos blocos econômicos e das contradições da globalização neoliberal. Destacam-se as proposições articuladas na União Européia para a organização do modelo social europeu, incluindo seus problemas e perspectivas. Aborda-se também a discussão sobre a proteção social nos países do Mercosul que, embora não tendo ainda a densidade analítica do debate europeu, permite identificar pontos comuns no desenho das políticas sociais públicas e direitos sociais no cenário contemporâneo. Concluindo, apresentamse alguns desafios que esta realidade coloca para o campo da pesquisa no Serviço Social.

Palavras-chave: blocos econômicos, proteção social, Serviço Social.

\section{astract}

This article presents elements for the debate about the proposals related to social protection that have been identified in the context of regional economic blocks and of the contradictions for neoliberal globalization. These are highlighted by the proposals articulated in the European Union for the organization of the European social model, including its problems and perspectives. The paper also discusses social protection in the Mercosur countries where, although there is not the same intensity of analysis as in the European debate, it is possible to identify common points in the design of contemporary public social policies and social rights. In conclusion, the paper presents some challenges that this reality presents to research about Social Work.

Key words: economic blocks, social protection, Social Work.

\section{Ivete Simionatto}

Doutora em Serviço Social, PUC/SP.

Pós-Doutora, European University Institute, Florença - Itália.

Professora do Dep. de Serviço Social e do Curso de Pós-Graduação em Serviço Social, UFSC.

\section{Vera Maria Ribeiro Nogueira}

\section{Doutora em Enfermagem, UFSC.}

Professora da Universidade Católica de Pelotas-RS e do Programa de PósGraduação em Serviço Social, UFSC. 


\section{Introduçăo}

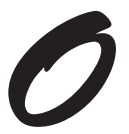

s desdobramentos da agenda neoliberal no tocante às reformas do Estado, iniciadas nas últimas décadas do século XX, e o rompimento com o pacto fordista-keynesiano conformaram, em vários países, um novo desenho nos padrões de proteção social. Tanto na Europa através do Tratado de Maastricht e na América Latina através das orientações do Banco Mundial, as agendas governamentais buscaram articular uma proposta de "welfare compatível" sob os ditames do ajuste fiscal. As dinâmicas expansivas na área social, consideradas as principais responsáveis pelo crescente desequilíbrio das finanças públicas ocasionaram uma acelerada redução dos investimentos nas políticas sociais de caráter universalista não apenas no continente latino-americano, mas também nos países integrantes da União Européia (UE). As conseqüências de tais encaminhamentos começam a ser pesquisadas, cabendo ao Serviço Social identificar as demandas no campo de sua competência profissional. Neste sentido, esse trabalho pretende pontuar algumas questões colocadas hoje ao Serviço Social, na perspectiva de atualizar as agendas de investigação sobre temas pertinentes à ação do assistente social.

Entende-se que os processos vivenciados na realidade européia fornecem pistas para pensar os novos desenhos de proteção social na América Latina e, portanto, também no bloco regional do Mercosul considerando a antecedência das medidas de ajuste implementadas, permitindo análises e críticas sobre as novas relações entre o Estado e a sociedade civil no campo da proteção social. Essas análises e críticas podem contribuir para problematizar a questão social no continente latino-americano, lembrando sempre das disparidades regionais.

As indicações contidas no presente texto foram resgatadas do debate ocorrido no Seminário Fronteira Mercosul: as interfaces entre o social e a saúde $e^{1}$, promovido pelo Núcleo de Estudos Estado, Sociedade Civil e Políticas Públicas (NESPP), do Departamento de Serviço Social da Universidade Federal de Santa Catarina e da participação em fóruns acadêmicos sobre o tema.

\section{A proteção social na realidade européia}

O welfare state europeu sofreu, desde os anos 1980 , reduções significativas, provocadas pela agenda neoconservadora, embora de formas diferenciadas nos seus Estados-nação. Os elementos que fundamentavam o modelo social europeu até esse período incluíam o forte compromisso do Estado na garantia de elevados níveis de segurança social a todos os cidadãos através de políticas de proteção social universalista como base da garantia de direitos e de fortalecimento da cidadania social. Tal modelo pautava-se ainda em uma forte solidariedade nacional no tocante ao estabelecimento das políticas fiscal e econômica, preservando-se a centralidade da esfera pública e o controle da participação do mercado na provisão de bens e serviços sociais (DE SOUSA SANTOS, 2001). Analistas como Paul Ginsborg (1998) e Massimo Pacci (1996) indicam que o welfare state europeu, de modo geral, considerando-se suas particularidades, marcou, até a década de 1980, presença efetiva em áreas cada vez mais vastas da vida social como saúde, previdência, educação, habitação e transporte.

Mas é precisamente na esteira da política neoliberal que essa perspectiva vem se alterando gradativamente e redirecionando as agendas políticas de muitos países da UE no campo do welfare state. A questão social na Europa, nos dias de hoje, não consiste somente na exclusão de um grande contingente populacional, vítimas da nova ordem econômica, mas também da progressiva erosão dos benefícios sociais e das garantias anteriormente existentes (PAVOLLINI, 2002). A pobreza e a exclusão tendem a crescer junto a faixas da população vinculadas à chamada classe média, igualmente atingida pelos fenômenos de precarização socioeconômica. Verifica-se, ainda, a elevação das taxas de desemprego entre os jovens e a instabilidade laboral com a ampliação de contratos de trabalho por tempo determinado.

Além do desemprego outra questão preocupante está relacionada ao aumento do número de pessoas denominadas de "não auto-suficientes", ou seja, de pessoas com dependência parcial ou total de terceiros, cujos cuidados têm recaído, principalmente, sobre as famílias ou em redes informais. No ano 2000, segundo os dados da Organização de Cooperação e de Desenvolvimento Económicos (OCDE), essa população atingiu $16 \%$ nos países da UE, estimandose a cifra de $21 \%$ até o ano 2020 . Aumenta neste campo a demanda por serviços na área da saúde, especialmente os de internação hospitalar e de assistência social, o que implica na necessidade de incremento dos serviços de natureza pública e de cobertura dos planos de saúde.

As exigências de inovações institucionais nos sistemas de proteção social apontam ainda para ações relativas à população imigrada de primeira e segunda geração. Este fenômeno transversal implica em intervenções não apenas no campo socioassistencial imediato, mas igualmente em políticas sociais de natureza pública, como saúde, educação, habitação e previdência social. Esse contingente populacional formado por pessoas de países diversos não constantes do bloco da UE incide, ainda, no mercado de trabalho, criando a figura do trabalhador atípico e do trabalho ilegal.

É justamente a partir desse quadro que se situam as proposições para a construção do "modelo social europeu" e de reorientação dos sistemas de welfare state. As 
propostas que vêm sendo discutidas têm levado em conta a situação dos diferentes Estados-nação e seus respectivos modelos de proteção social frente às políticas restritivas, ocorridas com o processo de globalização e formação dos blocos econômicos.

Sobre esse aspecto é importante recuperar que as reformas do welfare state e o delineamento de uma política de seletividade e restrição da intervenção pública, funcionais ao ideário de contração dos gastos, foram aprofundados com as orientações do Tratado de Maastricht, assinado em 1992, em que os países europeus, a fim de equilibrar as contas públicas, cortaram praticamente quaisquer perspectivas de ampliação dos investimentos na área de proteção social (RAVAIOLLI, 2002). Assim, no decorrer dos anos 1990, com as exigências do Tratado, evidencia-se em toda a Europa que, não obstante a defesa de um Estado social voltado ao desenvolvimento econômico, à estabilidade e ao aprofundamento da democracia e da justiça social, pilares da civilização européia, este deveria ser compatível a uma economia de mercado competitiva (AGLIETA; LUNGHINI, 2001, ARCOCELLA, 1999). O Tratado de Maastricht, concebido como um projeto de integração política e econômica, encaminhou-se, cada vez mais, para uma união monetarista, distante das particularidades das economias reais de cada país. Nesse sentido Moreno (2004) observa que as políticas macroeconômicas se decidem no âmbito europeu e as políticas sociais são determinadas no interior dos Estados nacionais. Relata, ainda, que persiste uma certa dicotomia entre as orientações econômicas e o modelo social europeu. Autores como Bertola, Boeri e Nicoletti (2001) indicam que as rígidas medidas impostas no âmbito do pacto de estabilidade para os países membros da União Européia, os critérios de Maastricht e a adoção da moeda única levaram os governos a adotar medidas do lema tatcheriano, ou seja, "não há outra alternativa", devendose dar maior atenção às políticas macroeconômicas.

O modelo de welfare europeu, entretanto, a partir desse período, passou a ter grande similitude com o dos Estados Unidos, adotando-se uma perspectiva ideológica e cultural dualística, em que, ao lado de um setor público redimensionado, com finalidade de assistência aos pobres, buscou-se desenvolver um forte setor de seguridade privada. Em um contexto em que a questão social tornavase mais dramática, encolheram, paralelamente, os programas de proteção social, limitados cada vez mais à assistência básica, com o objetivo de manter a coesão social. Saúde, educação, assistência e previdência são pensadas não como bens coletivos e necessários a todos, mas através de umas óticas excludentes, afeitas às regras de mercado (BARCELLONA, 1998, 2000).

No cenário contemporâneo, a organização do "modelo social europeu" tem sido recolocada no debate, mediante a mobilização de pesquisadores e especialistas em políti- cas sociais que defendem a construção de novas bases para a UE, assentadas no compromisso em preservar os padrões de proteção social historicamente conquistados e não o recuo dos mesmos, conforme as diretrizes da política econômica (FERRERA; HEMERIJCK; RHODES, 2000).

Para De Sousa Santos (2001), o acúmulo políticoinstitucional dos países da UE, mesmo considerando as necessidades legais em relação à política macroeconômica e a compatibilidade dos mercados, permite pensar a construção da chamada Europa Social que preserve as conquistas sociais obtidas no período pós-guerra.

Compõe a agenda central desse debate a organização de um "modelo comum" de proteção social para todos os países do bloco, onde o componente universalista do welfare state e a continuidade de manutenção de "níveis elevados de proteção social" aparece ao lado das preocupações provocadas pelas mudanças que atingem todos os países, conforme indica o relatório da Comissão Européia (1999, p. 3):

Os sistemas de proteção social dos EstadosMembros enfrentam um conjunto significativo de desafios comuns, nomeadamente a necessidade de se adaptarem a um mundo do trabalho em mutação, às novas estruturas familiares e às dramáticas alterações demográficas das décadas que se avizinham. Em simultâneo, devem conciliar os desejos claramente expressos pelos cidadãos no sentido da continuação de níveis elevados de proteção social com a necessidade de tornar os serviços púbicos mais eficientes e cumpridores do rigor orçamental.

Outras análises apontam, no entanto, que a Europa da "coesão social" ou dos fortes Estados de Bem-Estar (ainda que existam diferenças entre os países) está submetida a um brutal desmantelamento. O conjunto de direitos sociais, obtidos e desenvolvidos de maneira desigual e através de processos diversos no continente europeu, está em grave perigo e pode desaparecer. Sua perda reduziria os níveis civilizatórios alcançados e traria graves conseqüências sobre a democracia formal, já em regressão (BUSSEMAKER, 1999).

Reconhece-se que a manutenção de níveis elevados de proteção e a ampliação dos serviços públicos para a garantia dos direitos sociais dependem, no entanto, de alterações substanciais, nos campos econômico, político e social, contraditórias à programática de cunho neoliberal em grande medida assumida pela maioria dos países ao largo dos anos 1990 (TRENTIN, 1998).

A construção da Europa Social remete à discussão das particularidades dos Estados mais pobres e com sistemas de proteção social de menor abrangência como Portugal, Grécia, Espanha e, mais particularmente, com a entrada 
de novos países ocorrida em maio deste ano, como Polônia e outros do antigo eixo comunista, aumentando, significativamente, a população do bloco europeu. Mesmo considerando as diversidades dos sistemas de proteção social dos Estados-membros a possibilidade de um futuro comum para uma Europa Social tem se apresentado como tema recorrente no contexto das mudanças em curso uma vez que após o Tratado de Maastricht apenas progressos descontínuos e ocasionais ocorreram na definição da chamada cidadania social.

De Sousa Santos (2001) defende a construção de um "modelo social europeu" capaz de reforçar o componente da solidariedade através de duas estratégias: a primeira, que abrangeria toda a sociedade seria de caráter nãocontributivo, financiado pelo orçamento europeu; a segunda, de natureza contributiva, abrangeria, obrigatoriamente os titulares de todas as formas de rendimento (incluindo as de capital) e com taxas de substituição regressivas

Pavollini (2002) indica que a construção de um novo modelo social europeu implica resgatar as formas históricas de tratamento da pobreza verificadas nos diferentes países da Europa, pois enquanto para uns tal tratamento se efetiva mediante o respeito aos direitos sociais de base para qualquer cidadão, em outros ocorre através de políticas sociais seletivas e focalizadas. Nesse contexto as formas de intervenção estatal e a elaboração de políticas públicas no cenário europeu carecem de acordos e pactos entre países pobres e ricos.

Autores como Bertola, Jimeno, Marinon e Pissarides (2001), Boeri (2001) e Nicoletti (2001) propõem uma política de proteção social para toda a Europa mediante uma tipologia de mínimos sociais, assentada no critério de renda familiar e endereçada aos segmentos pobres, ou seja, um sistema básico de assistência social. Um programa de solidariedade social comum a todos os países, impediria, na visão dos autores, a mobilidade populacional em busca dos serviços oferecidos em outros países e regiões. Para EspingAndersen (2001), no entanto, algumas restrições podem ser apontadas na proposta dos autores e na excessiva confiança que apresentam nos programas assistenciais como forma de promover a inclusão social. Para o autor a simples adoção de programas assistenciais não se apresenta como a melhor escolha para combater a exclusão. A assistência baseada em critérios de renda é um instrumento ineficaz contra a pobreza ou a exclusão uma vez que não garante o investimento público suficiente e ainda determina formas de estigmatização, criando armadilhas indesejadas ou apenas cobrindo os buracos na rede de proteção dos Estadosnação. Para Andersen, os melhores programas para combater a pobreza e a exclusão são os de caráter universal. Países como a Dinamarca e Suécia, por exemplo, investem menos em programas assistenciais considerando seus modelos de welfare state. Nesse sentido, até que ponto é desejável a construção de um Estado social europeu integra- do? Até que ponto os riscos de pobreza e de exclusão precisam ser tratados em nível supranacional?

Para Esping-Andersen (2001), a argumentação em favor de uma política social coordenada em nível europeu depende de como serão enfrentados os desafios emergentes no cenário atual tais como: envelhecimento da população, famílias instáveis, trade-off entre igualdade e emprego, dentre outros. Esses desafios ou problemas que os atuais sistemas de welfare tem enfrentado remetem à algumas conclusões: primeiro, a emergente concentração de riscos sociais que diverge drasticamente do objetivo presente na época em que tais sistemas foram criados. Os atuais Estados sociais foram construídos com base na perspectiva de que a maior parte dos indivíduos fossem apoiados em suas necessidades de bem-estar ao longo de seu ciclo vital. Assim muitos modelos de welfare são essencialmente ancorados em sistemas de aposentadorias. A manutenção desse modelo, de acordo com EspingAndersen, tem ocasionado o aparecimento de riscos em outra faixa etária, a dos jovens. Na faixa entre 20 e 30 anos aumentam consideravelmente as situações de desemprego, instabilidade familiar, trabalhos precários, e os Estados sociais, em toda a Europa têm oferecido poucas alternativas diante do agravamento desta situação. Segundo, a questão social mais importante hoje se refere às oportunidades de trabalho e inclusão no sentido de diminuir o trade-off entre igualdade e emprego, ou seja, como superar as situações de desemprego ou trabalhos precários com baixa remuneração. Assim, para o autor, o objetivo prioritário da política social européia não diz respeito aos custos com a proteção social, mas de que forma podese construir uma agenda direcionada à questão dos jovens, dos idosos e à qualificação para o trabalho.

Para Arcocella (1999), o novo modelo social europeu vem indicando a necessidade de interação entre Estado, sociedade civil e mercado, que renuncia definitivamente à função redistributiva do Estado, buscando implementar um sistema inspirado na idéia de subsidiariedade estatal em relação à iniciativa privada. $\mathrm{O}$ critério adotado é uma triangulação entre Estado, mercado e terceiro setor, com uma particular atenção ao voluntariado de base familiar, promovendo-se um verdadeiro mercado de serviços sociais, orientado à produção de programas não mais dirigidos ao cidadão, mas a pessoas individualizadas no contexto da família. Entende o autor que ocorre, assim, o desmantelamento dos direitos universais, conquistados mediante um século de lutas, em nome de uma oferta de serviços voltados mais especificamente para as famílias pobres e administrados por outras famílias. Critica a intervenção estatal somente onde o mercado e a família não conseguem chegar, uma vez que reafirma o modelo de welfare mix, pautado na "complementaridade compensatória" entre sujeitos públicos e o denominado "mercado privado social”, expressão das armadilhas do projeto neoliberal. 
Observa-se, em vários países europeus a construção de novos sistemas de welfare mix em que os serviços sociais organizam-se a partir da integração das redes familiarparenterais e comunitárias, fundadas sob uma ação voluntária e solidarista, com a participação dos setores público, privado e privado-social. Tal perspectiva busca redirecionar os objetivos das políticas públicas, acrescidas de um processo de descentralização em que as comunidades locais possam autotutelar-se e auto-organizar-se, a partir de um sistema de subsidiariedade onde a área privada, com e sem fins lucrativos, passaria a desempenhar papel de destaque.

A discussão sobre o Estado social europeu tem colocado em cena, além das particularidades de cada país em relação aos seus respectivos modelos de proteção social, a necessidade de introdução de mecanismos para atender uma nova demanda. Trata-se da população imigrante, o que exige novas formas de intervenção social e a definição dos direitos e deveres recíprocos entre os diferentes países. Semelhante situação também vem ocorrendo com a população de fronteiras entre Brasil, Argentina e Paraguai, países integrantes do Mercosul.

Nesse campo observa-se que as margens de manobra e pactuação na UE diferenciam-se em larga medida dos países latino-americanos, com alta dívida externa e subordinados aos constrangimentos dos organismos internacionais. Se nos países da UE tem-se como indicativo a possibilidade de compatibilizar o aumento da competitividade e o crescimento econômico com índices mais elevados de proteção social, o mesmo não se verifica nas recomendações do Banco Mundial para a América Latina.

\section{A realidade do Mercosul}

Mesmo considerando que a agenda e o tempo das reformas em andamento no âmbito da União Européia não possuam equivalências para outras regiões, a experiência pode trazer contribuições para pensar cenários emergentes como o Mercosul e as formas de revisão dos padrões de proteção social em países que não atingiram os patamares característicos dos modelos clássicos de welfare state.
A construção do bloco Mercosul, tal como a União Européia, tem seu início demarcado pelas contradições da globalização neoliberal. É igualmente sob este ideário que se embasam os diagnósticos, proposições e debates relativos às funções e papéis do Estado e sua respectiva agenda pública. Não só os países integrantes do Mercosul entraram em sintonia com as transformações ocorridas no mundo todo, mas também a América Latina em toda a sua extensão. As mesmas iniciativas perpassaram as reformas do Estado com amplos cortes nos gastos públicos e incremento às privatizações e desregulamentação.

No tocante à agenda social, deve-se recordar que, de forma semelhante à Europa, os países que integram o Mercosul apresentam diversidades quanto à situação econômica e à proteção social. As divergências tornamse marcantes quando se identifica que o Uruguai e a Argentina detinham, até a década de 1990, padrões de proteção social pública compatíveis com os da Espanha e da Itália. Seus indicadores sociais os colocavam em situação privilegiada ante os demais países latino-americanos. Do mesmo modo, os dois países possuíam uma cultura política fundada em princípios solidários, com o reconhecimento da igualdade social em termos de direitos sociais e do dever do Estado na sua garantia.

Os impactos do ajuste no conjunto dos países do Mercosul, ocorridos nas ultimas décadas, com perdas consideráveis nas formas de proteção social construídas em períodos anteriores e na retração das políticas sociais públicas, tornaram mais crítica a situação de pobreza e desigualdade. Os indicadores apontam o crescimento dos segmentos populacionais situados na faixa de extrema pobreza, que é agravada pela precarização das relações de trabalho, pelo desemprego, pelo número expressivo de jovens sem esperanças futuras e pela participação de crianças e mulheres no mercado de trabalho para ajudar na renda doméstica. A alteração de fatores demográficos, como o envelhecimento da população e o aumento dos índices de natalidade, vêm ocasionando novas demandas para o setor saúde. Tais aspectos ampliaram, significativamente, a demanda sobre a seguridade social pública.

Evidencia-se que as agendas das reformas do Estado, predominantes nos anos 1990 em todos os países do 
Mercosul, pautaram-se pelos mesmos princípios, agrupando-se em duas modalidades: uma, que ocorreu de forma explícita e implicou em mudanças na estrutura normativa e organizacional das instituições e, em alguns casos, na eliminação das mesmas. Outra, que alterou o padrão de normalidade do funcionamento institucional mediante a modificação de recursos técnicos e simbólicos, o fomento da competência em áreas historicamente pertencentes à esfera pública e a segmentação das demandas em serviços que tradicionalmente eram homogêneos. São as denominadas reformas residuais que, na maioria das vezes, abrem caminho para as reformas explícitas (LO VUOLO, 1994).

Nessa mesma linha de raciocínio, Soares (2000) indica dois traços comuns que caracterizaram o perfil das políticas sociais na América Latina: o primeiro, é de natureza pró-cíclica ou regressiva, tanto em relação ao gasto como ao financiamento do setor social, reduzido a mecanismos compensatórios mínimos; o segundo, é o esvaziamento do orçamento dos setores sociais, com cortes em programas destinados aos segmentos de classe mais subalternizados e com menor poder de pressão, o que impede a expansão dos serviços e produz a sua saturação pelo excesso de demanda.

Essas indicações possuíam como denominador comum a contenção do gasto público, principalmente em áreas sociais, o fomento à privatização, o corte dos direitos sociais e a redução do acesso aos serviços e benefícios. As políticas sociais públicas passaram a concentrar-se em programas nitidamente assistenciais, com o objetivo de compensar os efeitos negativos das políticas econômicas restritivas. Em todos os países do Mercosul, a focalização do gasto social em programas públicos-alvo foi a regra geral, mantendo-se, inclusive, nos dias atuais.

O lugar das políticas sociais públicas nos países do Mercosul, portanto, passou a situar-se cada vez mais para fora do Estado, reduzindo os direitos de cidadania e ampliando o fosso entre sociedade política, sociedade civil, governantes e governados. Reformado pelo alto, sem qualquer discussão democrática e excluindo a participação popular, as reformas consagraram o "Estado hobbesiano", desqualificando a política e a democracia.

Em que pese a proposta de crescimento econômico com eqüidade da Comissão Econômica para a América Latina (CEPAL), na década de 1990, a tônica foi o receituário proveniente do Consenso de Washington e as críticas quanto aos desdobramentos de tais iniciativas, desqualificadas nos planos nacionais. As medidas adotadas ampliaram os níveis de desigualdades regionais no interior dos países e entre os mesmos, havendo o reconhecimento da perversidade do modelo até mesmo pelos seus mentores intelectuais.

Essa situação provocou um redirecionamento da agenda do Mercosul no sentido de buscar o desenvolvimento econômico com justiça social, democracia e fortalecimento das instituições no bloco regional, conforme posição dos presidentes dos países integrantes, por ocasião da XXVIII Reunião do Conselho do Mercado Comum, realizada em 2005 .

Concluindo, ainda que se considerados os contextos sociopolíticos, econômicos e institucionais distintos entre os países do Mercosul e da União Européia e as características desiguais entre países e regiões, pode-se indicar alguns traços e tendências comuns no desenho das políticas sociais públicas que indicam uma outra configuração aos direitos sociais no cenário contemporâneo, a saber:

a) política de seletividade e restrição da intervenção pública, funcionais ao ideário de contração do gasto público sob as orientações do Tratado de Maastricht na Europa e do Consenso de Washington na América Latina em que, os países, para equilibrar as contas públicas, cortaram praticamente qualquer perspectiva em futuros investimentos na área de proteção social;

b) revisão das relações entre público e privado, mediante a ampliação das funções dos sujeitos privados e do setor sem fins lucrativos que configuram o chamado welfare mix, reduzindo a possibilidade de garantia legal de direitos;

c) incremento à participação das organizações nãogovernamentais e da família na execução de programas socioassistenciais;

d) concentração dos investimentos nas chamadas políticas sociais básicas, como alimentação e atenção primária à saúde, com implicações negativas enquanto estratégia de superação da pobreza atingindo, principalmente, os países da América Latina;

e) bifurcação crescente entre as esferas nacionais e internacionais, entre os objetivos das políticas macroeconômicas e os objetivos sociais, subordinando estes últimos aos pressupostos das agências multilaterais;

f) ênfase em políticas focalizadas e compensatórias, alterando-se a concepção de universalidade, que passa a ser entendida como universal para os que dela precisam;

g) uma ressignificação dos direitos sociais, confirmando-se a redução da esfera pública e retornando-se a patamares desiguais de cidadania (ESPINGANDERSEN, 2001).

\section{Novos cenários - novas agendas para 0 Serviço Social}

A partir dos anos 2000, tendo em vista os novos ordenamentos sociais e econômicos, intensificaram-se os debates no campo das ciências sociais, levando a academia e as diferentes profissões da área social a se debruçarem sobre os possíveis cenários para a América Latina. 
Esse fato tem sido evidenciado em diferentes fóruns nacionais e internacionais, destacando-se entre eles o Seminário Fronteira Mercosul: as interfaces entre o social e a saúde. Na ocasião, pesquisadores e representantes de associação dos assistentes sociais (ADASU, 2005) dos países integrantes do Mercosul debateram o rumo das pesquisas fazendo um balanço do estado da arte relacionando o social e a saúde. Essa relação não significa afirmar que a saúde não está implícita no campo social, mas sim marcar em como as novas determinações sociais incidem direta e perversamente no campo da saúde. De forma inequívoca se repõem, na América Latina, a confluência perversa entre as políticas macroeconômicas e os padrões de proteção social construídos a partir do modelo keynesiano.

No Seminário, acima indicado, os debates e as reflexões apontaram vários aspectos que confirmam o exposto anteriormente. Dentre esses, destacam-se os arrolados a seguir.

Contraditoriamente, os processos de integração regional colocaram em cheque as evidências do direito como um direito limitado à idéia de nacionalidade, de uma cidadania construída sobre o Estadonação. Essa premissa, afirmada no campo econômico, é desconsiderada no campo social. Enquanto as políticas econômicas sugerem processos de regionalização e globalização, sendo definidas em um plano supranacional, as políticas sociais ainda são de competência dos governos nacionais, mantendo-se o estatuto de cidadania social restrito ao Estado-nação.

Acentua-se o paradoxo entre as exigências nacionais para manterem os níveis exigidos pelas determinações supranacionais no campo econômico e as dificuldades para manutenção da proteção social para segmentos populacionais cada vez mais amplos. A "grande resposta" às dificuldades dos governos nacionais é oferecida pelas agências multilaterais na forma de transferência da proteção social para a sociedade civil.

As referências teóricas recentes sobre harmonização da proteção social nos blocos regionais vêm debatendo a importância dos sistemas de valores, ou seja, o patamar de solidariedade que se quer alcançar, visto que as distinções entre os países são gritantes. As diferenças repousam não apenas no acesso aos serviços e ações nas políticas públicas, mas igualmente na qualidade de vida da população. Nessa linha, a discussão sobre o alcance dos direitos é o ponto de partida para a harmonização efetiva.

- A satisfação de necessidade via competição aberta de mercado, a desregulamentação e flexibilização do trabalho vêm ocasionando a expansão da pobreza com novas características: maior participa- ção feminina no mercado formal de trabalho; o aumento do número de maiores dependentes, redução do mercado de trabalho para trabalhadores não qualificados, a expansão dos serviços privados e a redução dos serviços públicos.

Sobressai-se, de forma cada vez mais intensiva, a interface entre a crescente exclusão social e a saúde, sendo que os dados de 2004 apontam que 46\% da população da América Latina e do Caribe não contam com seguro-saúde e 82 milhões de crianças não completam um programa de vacinação. (ESCAMILLA, 2005).

Acentua-se a dificuldade da proteção pública no setor, exigindo investimentos e ações relacionados à proteção social, especialmente com a saúde do trabalhador e com a saúde da família. Confirmase, nessa linha a posição e a preocupação do representante da OPAS no Brasil, evidenciada no Seminário Internacional para a Integração das Ações de Saúde nas Fronteiras Físicas do $M E R C O S U L^{2}$, alertando para a necessária inclusão da população nos debates sobre a questão social.

A questão das identidades nacionais e das relações interfronteiras merece um destaque especial, visto que tem implicações na operacionalização das políticas sociais. Na medida em que os sistemas de proteção social são construídos com base em valores, normas e princípios nacionais, garantindo um patamar de proteção compatível com a herança histórica, o confronto entre sistemas distintos, como ocorre na linha de fronteira, traduzse em obstáculos de ordem ética, moral, política e institucional. Tais obstáculos se repõem tanto para a população como para profissionais e gestores de políticas públicas.

Identifica-se, a partir do mapa antes traçado, inúmeros recortes de pesquisa que se vinculam diretamente à intervenção profissional do assistente social. Rotondi (2005), analisando o estado da arte das pesquisas na Argentina, a partir de estudo nas Universidades Nacionais de Córdoba, La Plata e Entre Rios, afirma que

[...] sin duda la llegada a la investigación de los TS se hace de la mano de las problemáticas sociales en las cuales los TS definen su intervención, y en las cuales los TS operan previamente a la inserción en investigaciones. Sin duda la cuestión social es un punto de articulación entre investigación y salud.

Os pesquisadores presentes no Seminário apontaram um amplo arco de temáticas relacionadas ao Serviço Social que vêm sendo desenvolvidas, como a per- 
sistência das pesquisas sobre as políticas universalistas; a gestão, o financiamento e controle social; a esfera pública não estatal e programas de geração de trabalho e renda, entre outras.

Evidenciou-se, em que pese a expansão rápida da pesquisa no âmbito do Serviço Social, algumas lacunas relacionadas a aspectos decorrentes dos encaminhamentos atuais da proteção social, tais como as situações vividas por sujeitos particulares. Também a avaliação das políticas sociais é um tema pouco presente na agenda dos pesquisadores.

Sintetizando, reconhece-se o avanço considerável ocorrido nas últimas décadas na produção do conhecimento sobre os processos de globalização e suas interfaces com os direitos humanos e sociais, a cidadania, a democracia, o Estado e a sociedade civil, o mundo do trabalho, as políticas sociais. Permanece, ainda, no entanto, um descompasso entre a produção de conhecimentos relativa aos "macroprocessos sociais" e sua mediação com as exigências do próprio campo profissional. Aponta-se, assim, para a exigência do aprofundamento de estudos que contemplem a relação destas dimensões com as particularidades que incidem sobre o exercício profissional, o reconhecimento do trabalho profissional como fonte de informação para a pesquisa, a criação de redes de investigação que vinculem o âmbito acadêmico e os campos de prática em nível regional com vistas ao aprofundamento de temas comuns e a criação de mecanismos institucionais que permitam maior intercâmbio entre instituições e pesquisadores.

\section{Recebido em 12.05.2006. Aprovado em 08.06.2006.}

\section{Referências}

ADASU. Las tendecias y las possibilidades de investigación sobre protección social y atención de la salud en Uruguay. In: Anais do Seminário Fronteira Mercosul - as interfaces entre o social e o direito à saúde. UFSC, Florianópolis, 2005.

AGLIETTA, M.; LUNGHINI, G. Sul capitalismo contemporaneo. Torino: Bollati Boringhieri, 2001.

ARCOCELLA, N. Globalizzazione e Stato sociale. Bologna: Il Mulino, 1999.

BARCELLONA, P. Il declinio dello Stato: riflessioni di fine secolo sulla crisi del projeto moderno. Bari: Edizioni Dedalo, 1998.

. L'individuo e la comunità. Roma: Edizione Lavoro, 2000.

BERTOLA, G; JIMENO, J. F.; MARINON, R; PISSARIDES, C. Sistema degli stati sociali i mercati del lavoro in Europa: quale convergenza e dopo l'Unione Monetaria Europea. In: BERTOLA, G.; BOERI, T.; NICOLETTI, G. (Orgs.). Protezione sociale, occupazione e integrazione europea. Bologna: Il Mulino, 2001.
BOERI, T. Conclusione. Quale ruolo per le istituzioni sovranazionali europee. In: BERTOLA, G.; BOERI, T.; NICOLETTI, G. (Orgs.). Protezione sociale, occupazione e integrazione europea. Bologna: Il Mulino, 2001.

BUSSEMAKER, J. Citizenship and Welfare State reform in Europe. London and New York: Routledge/ECPR, 1999.

COMISSÃO EUROPÉIA. Uma estratégia consertada de modernização da protecção social. In: FORUM Europeu de Políticas Sociais. Bruxelas, 1999.

DE SOUSA SANTOS, B. Globalização fatalidade ou utopia? Porto: Edições Afrontamento, 2001.

ESCAMILLA, J. A. Saúde e exclusão nas Américas. In: Anais do Seminário Fronteira Mercosul - as interfaces entre o social e o direito à saúde. UFSC, Florianópolis, 2005.

ESPING-ANDERSEN, G. Commento.In: BERTOLLA, G.; BOERI, T.; NICOLETTI, G. (Orgs.). Protezione sociale, occupazione e integrazione europea. Bologna: Il Mulino, 2001.

FERRERA, M.; HEMERIJCK, A.; RHODES, M. O futuro da Europa Social, repensar o trabalho e a protecção social na Nova Economia. Oeiras: Celta Editora, 2000.

GINSBORG, P. L'Italia nel tempo presente: famiglia, società civile, Stato. Torino: Einaudi, 1998.

LO VUOLO, R. M; BARBEITO, A. C. La nueva oscuridad de la política social. Buenos Aires, Ciepp, 1994.

MORENO, L. Reformas y reestructuración del Estado de Bienestar en laUnión Europea. In: BOSCHETTI, I.; PEREIRA,P. A.P.; CÉSAR, M. A.; CARVALHO, D. B. B. de. Política Social: alternativas ao neoliberalismo. Brasília: UnB, Programa de Pós-Graduação em Política Social, Departamento de Serviço Social, 2004, p. 39-60.

NICOLETTI, G; HAFFNER, R.C.G; NICKELL, S.; SCARPETTTA, S.; ZOEGA, G. Integrazione europea, liberalizzazione e performance del mercato del lavoro. In: BERTOLA, G.; BOERI, T.; NICOLETTI, G. (Orgs.) Protezione sociale, occupazione e integrazione europea. Bologna: Il Mulino, 2001.

PACCI, M. Un nuovo patto sociale per la riforma del welfare. Quale Stato. Trimestrale della Funzione Pubblica, n. 2, 3, p. 183193, Roma, CGIL, 1996.

PAVOLLINI, E. Il welfare alle prese con i mutamenti sociali: rischio, vulnerabilità, frammentazione. Rassegna italiana di sociologia, n. 4, Roma, 2002.

RAVAIOLLI, C. Un mondo diverso è necessario. Roma: Riuniti, 2002.

ROTONDI, G. As tendências e possibilidades de pesquisas sobre proteção social e atenção à saúde na Argentina. In: Anais do Seminário Internacional Direito à Saúde: interfaces entre o social e a saúde. Florianópolis, UFSC, 2005.

SOARES, L. S. Os custos sociais do ajuste neoliberal na América Latina. São Paulo: Cortez, 2000.

TRENTIN, B. Europa politica ed Europa sociale. Quale Stato, Trimestrale della Funzione Pubblica, n. 3, Roma, CGIL, 1998. 


\section{Notas}

1 O Seminário foi realizado entre os dias 23 e 25 de maio de 2005, na Universidade Federal de Santa Catarina, e contou com a participação de pesquisadores, representantes ministeriais e profissionais da área social.

2 Seminário Internacional promovido pela Escola Nacional de Saúde Pública (da Fundação Oswaldo Cruz - FIOCRUZ), Rede de Investigação sobre Serviços e Sistemas de Saúde no Cone Sul, com o apoio do Ministério da Saúde do Brasil e da OPAS/BR. Realizado no Rio de Janeiro, de 24 a 26 de março de 2006.

\section{Ivete Simionatto}

isimion@mbox1.ufsc.br

\section{Vera Maria Ribeiro Nogueira}

vera@mbox1.ufsc.br

Programa de Pós-Graduação em Serviço Social Mestrado

Universidade Federal de Santa Catarina

Centro Sócio-Econômico

Campus Universitário Reitor João David Ferreira Lima

Trindade - Florianópolis - Santa Catarina

CEP: 88040-900 